\title{
Analysis of the Application of Artificial Intelligence in College English Teaching
}

\author{
Dan Zhu \\ Changchun Institute of Technology, China
}

\begin{abstract}
Over the decades, the traditional method of teaching English in colleges has been widely criticized due to its various problems and shortcomings. This paper introduces the content of artificial intelligence, such as the concept, development and advantages of artificial intelligence, puts forward the artificial intelligence-based college English teaching system and analyzes the overall realization scheme of college English assistant teaching system based on artificial intelligence with a view to reducing the burden of teachers and improving teaching quality.
\end{abstract}

Keywords-artificial intelligence; teaching system; application

\section{INTRODUCTION}

With the rapid development of artificial intelligence and its extensive application in learning and life, the author finds out that the application of artificial intelligence in college English teaching not only directly affects the development of artificial intelligence in modern information education, but also has a significant impact on the equalization of education in the information society. The exploration of application must be from both the theoretical teaching and the practical teaching. Therefore, after summarizing the research results of experts and scholars at home and abroad and studying the basic connotation of artificial intelligence, this paper combines the artificial intelligence and the interactive development of college English teaching by means of literature analysis, observation, and field research. On the basis of analyzing the concept, development and advantages of artificial intelligence, this paper discusses the relationship between English teaching and artificial intelligence and the application of artificial intelligence in college English teaching. In addition, from the perspective of modern educational technology, the author explores the application of artificial intelligence in college English teaching, taking the comprehensive development of students as the fundamental starting point and destination. However, given the reality, artificial intelligence-based college English teaching system cannot completely replace the current teaching methods. After all, artificial intelligence technology has not yet achieved the simulation of all human intelligence. No matter what course it is, teaching should emphasize the subject of study. If the learners do not put any efforts, artificial intelligence will have little influence on teaching.

\section{THE ConcePt OF ARTIFICIAL INTELLIGENCE TECHNOLOGY}

Artificial intelligence refers to the computer application, in imitation of human intelligent behavior and the process of thought, forming a comprehensive discipline. It involves computer science, cybernetics, information theory, neurophysiology, psychology, philosophy, linguistics and other disciplines of mutual penetration on the basis of the development of a new emerging edge disciplines. By artificial intelligence, the human visual, touch, hearing, feeling, and thinking carry on the simulation, so as to realize the machine of artificial intelligence, enable people to solve problems in life and work, so as to ensure the safety of the people, improve the efficiency of people. As a new type of intelligent technology, the development of artificial intelligence is very fast. Artificial intelligence simulates people's working and living environment by using the computer system for the corresponding programming, with a view to completing intelligent, automated system operation. The process of producing and the applying artificial intelligence consists of many other disciplines, among which, the computer network technology is the most important. In a certain sense, the development of computer network technology is based on the artificial intelligence technology. In addition, in artificial intelligence, cooperation ability is indispensable, through the effective integration of resources among different users, information and resources can be exchanged. Artificial intelligence can connect the network management to optimize network management environment to achieve lower costs, improve efficiency, and so on.

\section{OVERVIEW OF THE DEVELOPMENT OF ARTIFICIAL INTELLIGENCE}

In the 1950s, the concept of artificial intelligence was first put forward, followed by a number of significant achievements, such as machine theorem proving, checkers program, solving procedures and so on. At this stage, artificial intelligence experts attached importance to the problem solving method, ignoring the importance of knowledge, causing the failure in machine translation, so that artificial intelligence was in the trough. From the late 1960s to the 1970s, the emergence of expert systems has led to a new upsurge in artificial intelligence research. With the development of the fifth generation computer, artificial intelligence has obtained great development. The main direction of artificial intelligence during this period is to create intelligent robots. In the late 1980s, neural network theory and technology were developing rapidly. By the 1990s, due to the development of Internet technology, artificial intelligence began to shift from single intelligent subject research to distributed artificial intelligence based on network environment. On the other hand, because of the continuous improvement of computer speed and the constantly expanding storage capacity, the computer hardware 
has rapidly improved. Therefore, artificial intelligence appeared a new climax. Some of these technologies have been practical, which enables artificial intelligence penetrates into various fields of social life.

\section{The Advantage of Artificial Intelligence TECHNOLOGY}

The application of computer network involves a real-time, instantaneous degeneration, therefore, could constantly improve the flexibility and diversity of management technology, thus better ensuring the stability, security and efficiency of the computer network. And artificial intelligence technology has many advantages, which can play an important role in computer network. Especially for system mathematical model, which needs a detailed description, artificial intelligence techniques with strong processing capacity, such as fuzzy logic, can be introduced into the intelligent network management, so as to make the network management have the capability of fuzzy information processing. Another important advantage of artificial intelligence technology is cooperation ability, which could better control and manage the inscrutability, uncertainty information, thus improving the efficiency of network system with its continuous expansion of network structure. What's more, the multi-agent collaboration distribution thinking of artificial intelligence, can realize better collaboration between all levels of management. Thanks to its strong reasoning, interpretation, learning ability, artificial intelligence can carry on the explanation to the low-level information and learning, and high-level reasoning concepts and information as well.

\section{Analysis of CuRREnt College English TEACHING}

With the continuous improvement of college English teaching level and the freshmen's English level, the Ministry of Education has stipulated the university syllabus, which has made new demands on college English teaching, and has higher requirements for non-English majors. In this case, the computer-aided college English teaching with multimedia technology and network technology support is developing rapidly. This teaching method aims to combine the traditional classroom teaching with modern information technology, and to complement the advantages of the online course and the traditional classroom. The current English computer-aided teaching exists various kinds of problems, which includes:

Firstly, lack of teachers. The increase in students and the small class of teaching in English caused a shortage of teachers, English teachers lack energy. To fundamentally solve this problem, we need to improve the quality of teaching and adopt targeted teaching.

Secondly, lack of solid basic knowledge. Under the reform of university teaching, the focus of English teaching has been shifted. Teachers have no time and energy to consolidate the basic knowledge of students, such as vocabulary, grammar, basic knowledge. To a certain extent, all the above hinders the improvement of students' English level. It is high time to help students consolidate the basic knowledge to further improve the quality of teaching.

Thirdly, lack of self-learning awareness. Self-study includes three processes: self-monitoring, self-guidance, selfstrengthening. Teachers should take planned and skillful methods to achieve automation learning of students, thus urging them to regularly arrange the learning time, so that students can achieve learning aims through self-monitoring, feedback and regulation.

\section{FEASIBILITY OF APPLICATION OF ARTIFICIAL INTELLIGENCE IN COLLEGE ENGLISH TEACHING}

As one of the most developed information technology, artificial intelligence has made breakthrough in the development of intelligent teaching system. It has proved that the application of technology has improved the teaching effect obviously. The English curriculum reform of higher education has emphasized the integration of information technology and English courses to enhance the effectiveness of English teaching, which brings unprecedented opportunities for the integration of artificial intelligence and English disciplines teaching. Artificial intelligence is a study of how to use computer simulation of human intelligence science. With the development of modern electronic computer technology, people are eager for the practical application of artificial intelligence, focusing on how to use artificial intelligence to change social production and lifestyle. Education is the cornerstone of social progress, so there is no doubt that the use of artificial intelligence should be first applied to the field of education and teaching. Secondly, the language is the most important part of human intelligence. Therefore, language learning has a close link to artificial intelligence research totem test, natural language processing, machine translation and speech recognition technology. This is why the application of artificial intelligence technology in language learning is a matter of course. At the same time, English communication ability has become a bottleneck in education system, which has become a hot topic for a lot of linguistic research and academic discussion. To sum up, the application of artificial intelligence needs to be fully employed in college English teaching.

\section{ANALYSIS OF ARTIFICIAL INTELLIGENCE-BASED COLLEGE ENGLISH TEACHING SYSTEM}

The whole system includes four kinds of users: system administrators, field experts, English teachers, students. When a user logs in, he has different module operating privileges, depending on their identity.

System administrator: mainly refers to the one specified by the system owners to conduct the daily maintenance of the system, whose duties include user management (to query, increase, delete, modify teachers, students, field experts), the question bank management (add, query, modify, delete), password modification and so on.

Field Expert: refers to the senior English teachers with many years of teaching experience, able to thoroughly analyze the English questions involved in the knowledge points. The main duties include knowledge bank maintenance (to add, query, modify and delete static knowledge bank and dynamic knowledge bank) and so on.

English Teachers: refers to ordinary English teachers. Each 
of them has designated classes and students. The main duties include test organization, test results upload, analysis of the grasp of the knowledge points of the designated student groups so on.

Student: refers to the ordinary students. The main duties includes participation in practice, self-diagnosis, history practice diagnosis, knowledge point intensive exercise and so on.

The system designed in this paper has four application modules, namely auxiliary teaching module, knowledge explanation module, exercise training module and environment simulation module. We can further analyze the specific functions of the four modules in the system. First of all, the user of the auxiliary teaching module is college English teachers, the main user of other modules are the students. In this module, the English teacher can arrange the teaching video through the system interface. The teacher can use the data technology to evaluate the overall situation of the English test, including the student's English test score, the student's knowledge system and the integrated capacity of language use for analysis and evaluation.

Secondly, with the help of knowledge explanation module, students can apply the knowledge learned by watching the video and previewing or reviewing the knowledge points in text; thirdly, students can test their own mastery or lack of basic knowledge by practicing exercise training module, which involves four aspects: English reading, listening, writing, and dialogue, aiming at a comprehensive study of students listening, speaking and reading ability. As for environment simulation module, when the students finish the exercises, the module will automatically generate the corresponding evaluation level and learning suggestions; In addition, teachers can achieve the paperless examination of students through this module. Because the examination system is based on a large, scientific examination system which offers detailed question analysis and test results analysis, therefore, these modules can not only provide a reference for English teachers to teach students, but also help learners simulate real learning environment.

\section{SigNifiCANCE OF APPLICATION OF ARTIFICIAL INTELLIGENCE IN COLLEGE ENGLISH TEACHING}

The reform in college English puts forward new requirements to the traditional English teaching mode, which requires the teaching mode to be adapted to the environment and continue to develop and innovate with the change of the environment. Therefore, the choice of the teaching mode should be the same, and the emphasis should be put on the following: the awareness of student's role; the cultivation of students' self-learning ability; the practice and application of English language learning; the simulation of English learning environment both inside and outside; and the use of modern educational technology to optimize English teaching. In college English teaching, the system can be used as teaching manager, teaching assistant and even as a teaching object to accompany students to learn, which completely changes the traditional classroom teaching methods, and gradually forms the combination of mixed teaching mode, that is, the combination of traditional classroom, network classroom and man-machine. Under this kind of mixed teaching mode, the relationship between the machine and the teacher, the machine and the student has undergone a subtle change, which means the intelligent system should help the teaching activity of the teacher and student, which also embodies the people-oriented, student-centered, innovative teaching model.

\section{CONCLUSION}

Artificial intelligence is a science which studies the laws of human intelligence. In the current society, artificial intelligence is widely applied in all areas of society. In people's daily entertainment, work and life, artificial intelligence has played an important role, such as expert system, intelligent electric appliance etc. The emergence of intelligent technology and application, not only makes the life of people convenient, but also facilitates the development of science and technology progress, which provides a good direction, especially in the field of English teaching.

This paper introduces the concept, development and advantages of artificial intelligence. It analyzes the problems of English teaching and puts forward the realization scheme of English teaching system based on artificial intelligence technology. The system consists of four modules: auxiliary teaching module, knowledge explanation module, exercise training module and environment simulation module. Combined with English teaching, the artificial intelligencebased college English teaching system will greatly facilitate the English teaching and learning.

This paper is the research result of Research on Constructing College English Experiential Autonomous Learning Model Based on Network Platform, which is The 13th Five-Year Education and Science Planning Project of Jilin Province in 2017.

\section{ACKNOWLEDGMENT}

At the point of finishing this paper, I'd like to express my sincere thanks to all those who have lent me hands in the course of my writing of this paper. I'm greatly grateful to those teachers and working staff especially those in the School of Foreign Languages. Without their help, it would be much harder for me to finish my study and this paper.

\section{REFERENCES}

[1] Tsiriga, V, Virvous, M.A framework for the initialization of student models in web-base intelligent tutoring systems User Modeling and User-Adapted Interaction, 2004

[2] SQA.NQ Review Investigation Report: Computing and Information Systems http: //www.sqa.org.uk/sqa/28.139.html

[3] Troxel. Rethinking networking architectures for cognitivecontrol. In Microsoft Research's Cognitive WirelessNetworking Summit. Snoqualmie, WA, 2008.

[4] V. Sesum-Cavic and E. K•uhn. Applying swarm intelligence algorithms for dynamic load balancing to a cloud based call center. In IEEE SelfAdaptive and Self-Organizing Systems Workshop on Self-Adaptive Networking, (New York, NY: IEEE Press),2010.

[5] Paolo Dario, Eugenio Guglielmelli, et al. Robotic for Medical Applications. IEEE Robotics and Automation Magazine, September 2009: 44-56. 